\title{
METÁFORAS E COMPARAÇÕES QUE ENSINAM A ENSINAR:A RAZÃO E A IDENTIDADE DA PEDAGOGIA NOS MANUAIS PARA PROFESSORES (1873- 1909)
}

\author{
Vivian Batista da Silva ${ }^{1}$ \\ Denice Barbara Catani
}

\section{RESUMO}

Estariam os manuais para professores mais próximos de um livro ou de um receituário? Partindo dessa pergunta, este artigo analisa cinco títulos publicados entre 1873 e 1909. Trata-se do Compêndio de pedagogia (Pontes, 1873); da Pedagogia e metodologia de C. Passalacqua (1887); das Lições de pedagogia, de V. Magalhães (1900); do Compêndio de pedagogia de D. Vellozo (1907) e do Tratado de metodologia de F. Carvalho (1909). Procuremos conhecer como são feitas as referências à pedagogia, sua razão e identidade. Nesses textos, ela aparece ora como ciência, ora como arte. Analisando as metáforas usadas para orientar os professores, é possível identificar imagens a partir das quais os saberes pedagógicos são definidos e apresentados como objetos de leitura para o magistério.

Palavras-chave: manuais pedagógicos, pedagogia, ensinar.

${ }^{1}$ Universidade de São Paulo (USP), São Paulo/SP, Brasil.

2 Universidade de São Paulo (USP), São Paulo/SP, Brasil. 


\title{
METÁFORAS Y COMPARACIONES QUE ENSEÑAN A ENSEÑAR:LA RAZÓN Y LA IDENTIDAD DE LA PEDAGOGÍA EN LOS MANUALES PARA PROFESORES (1873-1909)
}

\section{RESUMEN:}

¿Los manuales escolares son más parecidos a los libros o a los recetarios? A partir de ese cuestionamiento, este artículo analiza cinco títulos publicados entre 1873 y 1909. Se trata del Compêndio de pedagogia (Pontes, 1873); de la Pedagogia e metodologia de C. Passalacqua (1887); de las Lições de pedagogia de pedagogía, de V. Magalhães (1900); del Compêndio de pedagogia de D. Vellozo (1907) y del Tratado de metodologia de F. Carvalho (1909). Queremos conocer cómo son construidas las referencias a la pedagogía, su razón e identidad. En esos textos, ella aparece ora como ciencia, ora como arte. Al analizar las metáforas usadas para orientar a los profesores, es posible identificar las imágenes a partir de las cuales los saberes pedagógicos son definidos y presentados como objetos de lectura para el magisterio.

Palabras clave: manuales pedagógicos, pedagogía, enseñar.

\section{METAPHORS AND COMPARISONS THAT TEACH TO TEACH:THE REASON AND THE IDENTITY OF PEDAGOGY IN TEACHERS' GUIDES (1873-1909)}

\begin{abstract}
Would pedagogical manuals be closer to a book or a recipe? Taking this question as a starting point, this article analyzes five titles published between 1873 and 1909 - Compêndio de pedagogia by Antônio Marciano da Silva Pontes (1873) Pedagogia e metodologia by Camillo Passalacqua (1887), Lições de pedagogia by Valentim Magalhães (1900), Compêndio de pedagogia by Dario Vellozo (1907), and Tratado de metodologia by Felisberto de Carvalho (1909). By exploring the references to pedagogy in those texts, their reasons and identities, we observe that it is sometimes referred to as science, and sometimes as art. Moreover, through the analysis of the metaphors used in the teachers' guides, it is possible to identify the images from which pedagogical knowledges are defined and presented as reading material for the teaching practice.
\end{abstract}

Key words: pedagogical manuals, pedagogy, teach.

\section{MÉTAPHORES ET COMPARAISONS QUI ENSEIGNENT À ENSEIGNER:LA RAISON ET L'IDENTITÉ DE LA PÉDAGOGIE DANS LES MANUELS D'ENSEIGNANT (1873-1909)}

\section{RÉSUMÉ:}

Les manuels pour enseignants seraient-ils plus proches d' un livre ou d'un mode emploi? À partir de cette question, cet article analyse cinq titres publiés entre 1873 et 1909. Il s'agit de: 
Compendium de pédagogie (Pontes, 1873); Pédagogie et méthodologie de C. Passalacqua (1887); Leçons de pédagogie de V. Magalhães (1900); Compendium de pédagogie de D. Vellozo (1907) et Traité méthodologique de F. de Carvalho (1909). Nous essaierons de comprendre comment y sont faites les références à la pédagogie, leur raison d'être et leur identité. Dans ces textes, elle apparait soit comme science, soit comme art. En analysant les métaphores y utilisées pour guider les enseignants dans leur quotidien de travail, il est possible d'identifier les images à partir desquelles les connaissances pédagogiques sont définies et présentées comme des objets de lecture pour le métier d'enseignant.

Mots-clés: manuels pédagogiques, pédagogie, enseigner. 


\title{
DE COMO ENSINAR A ENSINAR, ELEMENTOS PARA UMA REFLEXÃO
}

\begin{abstract}
Um livro de cozinha é um livro? Comumente não se atribui esse título aos folhetos que explicitam usos, maneiras e técnicas. Todo objeto cuja finalidade/utilidade é abolida pelo uso, parcialmente ou não, não leva o nome de livro: para fazer funcionar uma máquina, aprender uma língua, saber dirigir, encontrar um endereço, lembrar-se de uma obra, viajar, fazer coleções, não há necessidade de "livros", mas sim de manuais, instruções de uso, anuários, guias, catálogos... Não mereceria o nome de livro aquele que conserva uma irredutível intransitividade, que mantém fechado o circuito que ele forma com o pensamento do seu leitor. A imagem do leitor "absorto", imóvel, passivo, ausente do mundo é a prova do livro. Então, a classificação hesita: fala-se do "livro prático", expressão que a partir de um certo momento parece substituir o termo "manual", termo no entanto muito interessante porque supõe que há livros que colocam a "mão na massa”.(RIVIÈRE, 2004, p. 449, tradução nossa)
\end{abstract}

As palavras de Rivière (2004) nos conduzem a interrogar em que medida um texto pode, de fato, ser considerado um livro. Elas são muito sugestivas para reflexões sobre outros textos, para além dos livros de culinária, que também se prestam a "guiar a ação", como é o caso dos livros que ensinam a ensinar. Para nós, a epígrafe de Rivière (2004) inspira a retomada de estudos realizados desde finais dos anos 1990 e que tomam os chamados "manuais pedagógicos" brasileiros como fontes e objetos de estudo (SILVA, 2001, 2005, 2017). Os trabalhos iniciais versam sobre 44 editados entre 1930 e 1971 (SILVA, 2001). Em seguida, a identificação dos manuais pedagógicos passa a incluir desde o mais antigo do qual se tem conhecimento, datado da década de 1870, até o século seguinte, quando a Escola Normal é substituída pelo curso de Habilitação Específica para o Magistério, com a Lei 5692 de 1971. O levantamento chega então a 55 títulos. Além de ampliar os manuais considerados para o caso brasileiro, as pesquisas adquirem uma dimensão sócio-histórico-comparada, para compreender os modos pelos quais esses livros participam do processo de desenvolvimento e expansão da escola moderna. Com isso, a seleção abriga mais 25 textos publicados em Portugal de 1870 a 
1970 (SILVA, 2005). Desde a dissertação de mestrado (SILVA, 2001), outras pesquisas mobilizam os manuais de pedagogia, didática, metodologia e prática de ensino (TREVISAN, 2007, VALDEMARIM, 2008, GARCIA, 2014, HEGETO, 2014). E convém lembrar ainda os estudos acerca de manuais de outras disciplinas, como a história da educação (DUARTE e GATTI JR., 2017, GATTI JR, 2007, GATTI JR., 2009, GATTI JR., 2017) ou aqueles que se dirigem aos jardins da infância (BASTOS, 2011). De fato, são muitas as perguntas que podem ser feitas a esse material, rico e complexo.

Mais especificamente, os estudos sobre manuais pedagógicos encontram-se atualmente consolidados, sendo notável o progressivo aumento do número de trabalhos desde a década de 1990. Como foi possível evidenciar a partir de levantamento bibliográfico anterior (TEIVE, OSSENBACH-SAUTER, 2016), ao longo de duas décadas, aproximadamente, diversos autores do mundo, particularmente a França, a Espanha e a Itália, tem se dedicado à conservação e a investigações nesse campo. O conjunto desses trabalhos indica que em 1870, marco inicial do presente artigo, outros manuais pedagógicos circulam aqui, para além daqueles elaborados por brasileiros, como é o caso do Curso normal para professores de primeiras letras, tradução francesa do texto do Barão De Gérando, publicada em 1839 (BASTOS, 1998), e do Curso prático de pedagogia destinado aos alunos nestas escolas normais primárias e aos instituidores em exercício, publicado por Daligault na França em 1861 e que já circulava no Brasil na década seguinte (SILVA, PEREZ, 2014).

A tese de livre-docência (SILVA, 2017), defendida junto à Faculdade de Educação da Universidade de São Paulo foi mais uma oportunidade de interrogar o material. O que une esses livros, publicados num espaço tão longo de tempo e por pessoas tão diferentes, em suas convicções e posições no campo educacional? Algumas respostas são possíveis, dentre as quais se assinala o objetivo que todos assumem de ensinar a ensinar. Qual é o seu conteúdo? Quais temas privilegiam no decorrer dos anos para formar os professores da escola 
moderna? Organizada pelo Estado em diversas partes do mundo desde o século XIX para atender a todos de forma pública, obrigatória e gratuita, essa instituição vem abrigando maneiras de ensinar que dão continuidade a experiências medievais, mas também trazem especificidades e projetos de renovação (DUSSEL e CARUSO, 2003). Ao se voltar o olhar para como os manuais pedagógicos participam do processo de construção da modernidade escolar, do qual eles também fazem parte, atenta-se para as orientações de organização do magistério a partir do princípio da homogeneidade das classes. Analisando os manuais pedagógicos, pode-se perguntar sobre os desafios postos aos professores, quando eles estudam disciplinas (CHERVEL, 1990) ligadas ao magistério, como é o caso da pedagogia, por exemplo. A maior parte desses livros, em seus prefácios, chamam a atenção para o caráter "modesto", de "resumos" do que há de "melhor" na bibliografia educacional, a partir do que trazem orientações para o exercício do magistério. Em suma, ensinam a ensinar.

A nossa retomada dos estudos sobre manuais pedagógicos se dá, aqui, à luz de novas incursões sobre o material. Eles poderiam ser chamados de "livros", como interroga Rivière (2004)? Para o que nos interessa, diriam alguns, seria mais valioso apanhar a discussão e as definições no território especializado das teorias e estudos sobre a leitura e os livros. Não o faremos neste momento porque queremos aludir a outras questões potencialmente acenadas, por exemplo, pelo autor. Experimentamos conduzir a análise a partir da proximidade aludida, muitas vezes, entre os manuais pedagógicos e os "livros de receitas", num tom quase sempre depreciativo, que toca no cerne do problema que nos interessa: estariam as proposições didáticas, reunidas nos livros da área educacional, limitadas a "instruções para o uso" em receitas e indicações para sua execução? Não se poderia responder a essa questão sem considerar a multiplicidade de formas e intenções que tanto os livros que ensinam a ensinar quanto os livros de culinária podem assumir.

$\mathrm{E}$ isso torna a pergunta mais instigante. Tomando em conta, por exemplo, a famosa Dona Benta, "o livro de receitas número um do Brasil", 
lançado em 1940, líder de vendas até o início dos anos 2010, temos diante de nós um impresso com 1056 páginas, nas quais são distribuídas receitas de carne, massas, doces, bolos, sucos (ver a $77^{\mathrm{a}}$ edição de 2013). Todas elas apresentam uma lista de ingredientes e suas medidas para, em seguida, descrever brevemente os modos de fazer, com indicações breves e nem sempre claras, sobretudo aos iniciantes na cozinha. Parece haver um espaço restrito para outras leituras além do passo-a-passo que se pretende regulamentar. Mas importante é reconhecer que os livros de culinária não podem ser limitados ao exemplo da Dona Benta. Hoje, as livrarias são abastecidas com títulos cada vez mais numerosos, assinados por chefs reconhecidos, em impressos que compõem coleções sofisticadas, ultrapassando a tradicional divisão doce/salgado. Seus livros favorecem uma leitura acessível a cozinheiros com maior ou menor prática, porque as receitas costumam ser mais bem explicadas. Os livros tendem a ser mais atrativos, articulando as receitas com histórias de vida3 ou organizando-as a partir de necessidades do cotidiano. Esses livros constituem, assim, diferentes modalidades de leituras, favorecendo outros caminhos para as suas apropriações.

Na segunda parte do volume dois da magistral A invenção do cotidiano, cujo subtítulo é "Morar, cozinhar", Michel de Certeau nos diz:

Saber fazer, aprender a fazer, dizer como fazer: a sucessão dos gestos que se encadeiam, o hábil movimento das mãos necessitam por sua vez das palavras e do texto para circular entre os que lidam na cozinha. Este texto tem sua língua e seu corpo de referência, como tem seus segredos e suas conivências - todo um saber "bem entendido" que a mais detalhada das receitas jamais conseguirá comunicar (1998, p. 287).

Se as comparações da pedagogia ou da ciência da educação e do ensino

\footnotetext{
${ }^{3}$ Nina Horta e Paola Carosella exemplificam a perspectiva do livro de culinária que se constrói em tom autobiográfico. A título de exemplo, ver os títulos: Não é sopa - Crônicas e receitas de comida (Cia das Letras, 1995) e O frango ensopado da minha mãe, (da mesma editora, 2015), ambos de Horta e Todas as sextas (Ed. Melhoramentos, 2016), de Carosella.
} 
com a arte culinária são muito conhecidas e até menosprezadas pelo que se considera sua obviedade, se examinarmos detidamente as observações de Certeau (1998) e as confrontarmos com os processos de produção e circulação dos manuais e com o estado dos estudos da área, reconheceremos que a delimitação feita por ele e aqui transcrita enuncia a problemática fundadora do sentido e alcance dos manuais e de uma didática e uma pedagogia como artes do fazer. E ao prosseguir com as ideias de Certeau (1998), vamos encontrá-lo retomando Wittgenstein para pensar as "regras" ou as leis da cozinha. Pois bem, mais tarde, a formulação de Scheffler (1974) também se avizinharia do que nos informa Certeau (1998). Tentemos explicitar. Falando sobre regras diversas para governar atividades, o filósofo da linguagem (SCHEFFLER, 1974) identifica o caráter arbitrário das regras gramaticais por oposição às regras da cozinha. Em certo sentido isso se deve ao fato das regras, no caso da cozinha, se orientarem pelos fins. "Cozinhando de acordo com as regras que não são as regras corretas, o resultado será um fracasso na cozinha; mas jogando xadrez com regras que não são as dele, você estará jogando um outro jogo; e falando de acordo com regras gramaticais diferentes destas ou daquelas, nem por isso você estará falando de outra coisa" (CERTEAU, 1998, p. 288). E prossegue Certeau: "Mas a receita de cozinha complica a situação, pois se trata através dela de 'falar em línguas' das ações, de dizer o estritamente necessário sem esquecer qualquer informação indispensável, de descrever sem ambiguidade e sem saltar nenhuma etapa...” (1998, p. 288). Não precisamos ir além na retomada, por ora basta pensar que a natureza da atividade de ensinar a ensinar (fim da pedagogia e também dos manuais) sugere que suas regras serão, como no caso da culinária, capazes de auxiliar na diminuição da possibilidade do fracasso, mas dificilmente garantirão, sem margem de erro, o êxito. Mais poderia ser imaginado em consequência das ideias apresentadas, por economia, diremos apenas que em alguns dos manuais do período aqui considerado as regras não se explicitam, mas se mostra um modelo a ser seguido, uma forma de fazer que é passível de ser copiada simplesmente.

As "artes de fazer" (CERTEAU, 1998) ainda nos conduzem a pensar que 
nos manuais pedagógicos, para além de um receituário construído por metáforas que ensinam a ensinar, habitariam proposições eivadas de moralismo e princípios disciplinadores de conduta. Os livros em pauta neste artigo dão pistas das "maneiras" ou "artes de fazer", como diria Certeau (1998), elaborando uma primeira formalização das práticas de ensinar. As páginas publicadas de 1873 até 1909 vinculam a arte de ensinar a uma missão e um sacerdócio. Tomado como uma espécie de religião, o ensino exigiria do professor modéstia, amor, paciência. Ser professor seria pôr a funcionar as atividades mais cotidianas das escolas modernas, a matéria a ser ensinada, as aulas, as maneiras de disciplinar os alunos ${ }^{4}$. Suas páginas atentam para tarefas que, sobretudo nos meios acadêmicos, costumam ser consideradas monótonas e repetitivas, desprovidas de inteligência e de imaginação (TARDIF, 2000).

A história da educação pode nos mostrar outros exemplos desse tipo de situação em discussões sobre a "utilidade" e a consistência da pedagogia. Ao sublinharmos sua razão e identidade, estamos nos referindo à lógica do que se fala sobre pedagogia. Diversas referências são encontráveis nos livros escritos para Escolas Normais e relatórios de inspetores e professores, no final do século XIX, em São Paulo, nos quais evidencia-se a acusação de que a pedagogia se constituiria em pura “verbiagem”, dispensável na formação de professores. Daí aos nossos dias, as acusações exibiram formas bastante familiares. A ligação desses debates com o reconhecimento da natureza científica da área também apareceu neste tempo. Muito se disse a propósito e pode-se também, no próprio interior dos livros examinados, reencontrar, de modo mais ou menos explícito, os vários aspectos da questão na tentativa de definir a pedagogia como uma circunscrição disciplinar (e científica). Circunscrição essa que conhece também determinantes socioeconômicos e históricos, a partir dos quais as afirmações dos profissionais especialistas configuram-se alinhadas a interesses pela manutenção das divisões e sua legitimidade. Antes que se pense que vamos nos

\footnotetext{
4 Essa é a ênfase dos primeiros manuais pedagógicos publicados no Brasil - mas note-se que em finais do século XIX já começam a se delinear as primeiras tentativas de evocar conhecimentos mais teóricos, notadamente a psicologia, nas Lições de pedagogia (MAGALHÃES, 1900).
} 
embrenhar na defesa desta ou daquela posição, cabe sublinhar: a questão é ambígua, muitas vezes retomada e tem um ar "fora de moda". Procuremos conhecer pela história da educação brasileira e no interior dos manuais pedagógicos como foram sendo feitas as referências ao caráter dos conhecimentos sobre o magistério.

Ao introduzir, em suas observações sobre a noção de "ensinar" e os usos do termo, a ideia segundo a qual o conjunto de regras que podem ser fornecidas sobre esta atividade para "guiar" a ação dos professores não sejam regras capazes de assegurar o êxito, Scheffler (1974) aproxima o ensino do que chama de uma arte prática e sustenta algo que auxilia no entendimento da natureza do que nos dizem os manuais pedagógicos. São suas palavras: "Enquanto arte prática, o ensino assemelha-se à medicina, à engenharia e à culinária, por exemplo. Todas essas artes, por outro lado, se distinguem da ciência, entendida como um corpo de afirmações que pretendem ser verdadeiras, sobre a base da melhor evidência disponível..." (SCHEFFLER, 1974, p. 87). A alusão à arte prática é prolongada pela consideração da ciência como conjunto de afirmações e do ensino como atividade. Sem ir mais longe, vale lembrar as inúmeras vezes que a educação já aspirou a apresentar-se como ciência de cujos saberes os manuais fariam a apresentação facilitada.

Isso nos conduz novamente à pergunta posta por Riviére (2004). Estariam os manuais para professores mais próximos de um livro ou de um receituário? Atentamos aqui para cinco títulos publicados entre 1873 e 1909. Trata-se do Compêndio de pedagogia (PONTES, 1873); da Pedagogia e metodologia (PASSALACQUA, 1887); das Lições de pedagogia (MAGALHÃES, 1900); do Compêndio de pedagogia (VELLOZO, 1907) e do Tratado de metodologia (CARVALHO, 1909). Procuremos conhecer como são feitas as referências ao caráter dos conhecimentos da pedagogia. Nesses manuais, ela seria ciência ou arte? As páginas que se seguem estão divididas em dois momentos. Primeiramente, examinam como esses livros desenvolvem os tópicos da pedagogia e metodologia, disciplinas que, nos programas das Escolas 
Normais e dos concursos de ingresso na carreira docente, dão conta das questões mais diretamente ligadas ao ensino (SILVA, 2018). Depois, localizam nessas lições, compêndios e tratados metáforas e comparações usadas para orientar os professores em seu ofício e que permitem identificar as imagens a partir das quais os saberes pedagógicos, sua razão e identidade, são definidos e apresentados como objetos de leitura.

\section{O ENSINO COMO OBJETO DE ENSINO}

O texto que funda a série dos manuais para professores no Brasil é da década de 1870, conforme já pudemos assinalar. Além deste, outros títulos foram sendo editados no Brasil, reunindo as lições sobre como proceder no magistério e divulgando as normas e condutas para os que têm a "missão" de educar. Segue-se uma breve descrição dos cinco manuais em pauta neste artigo:

1. A terceira edição do Compêndio de pedagogia de Antônio Marciano da Silva Pontes é de 1873. Foi publicada no Rio de Janeiro pela Tipografia da Reforma.

2. A Pedagogia e metodologia de Camillo Passalacqua data de 1887 (Rio de Janeiro, Tipografia a vapor de Jorge Seckler \& Companhia).

3. A primeira parte das Lições de pedagogia, publicada em 1900, é toda dedicada à psicologia e corresponde às lições ditadas pelo seu autor, Valentim Magalhães. professor da matéria na Escola Normal, no decurso do ano de 1899 (Rio de Janeiro, Laemmert \& Companhia).

4. Coordenado por Dario Vellozo, então lente catedrático de história universal e do Brasil do Ginásio Paranaense e da Escola Normal, o Compêndio de pedagogia foi aprovado pela Comissão e publicado em 1907 na cidade de Curitiba para ser "guia 
valiosíssimo do ensino e dos estudos na aula de Pedagogia” (p.10).

5. A terceira edição do Tratado de Metodologia, coordenada por Felizberto de Carvalho e revista por um professor (como se anuncia na capa do livro), é de 1909 e foi publicada no Rio de Janeiro pela Editora Francisco Alves.

Cada um à sua maneira, os autores ensinam a ensinar salientando a experiência, o fazer, a arte. A propósito desse primeiro momento de edição dos manuais, a tese Um inventário de saberes, um repertório de fazeres da autoria de Franciele Ferreira França (2019) ajuda a compreender os modos pelos quais os professores constroem o seu trabalho e nesse sentido chama a atenção para os elos de ligação entre a experiência, as práticas e os saberes que vão sendo articulados para a formação e o exercício do trabalho.

Ensinar os professores a exercerem o magistério é a preocupação principal do Estado que, desde 1827 - data da primeira Lei de Ensino brasileira - vem se organizando para estruturar e expandir a rede de escolas. O esforço é notável à época em outros países também, configurando a instrução secular, obrigatória, gratuita, leiga e destinada a todas as crianças. Conhecido como o fenômeno da escola de massas (mass schooling) (NÓVOA e SCHRIEWER, 2000), ele instaura a modernidade educativa e envolve iniciativas, como a promulgação de leis, a construção de prédios escolares, o progressivo aumento do número de matrículas, bem como o recrutamento e formação dos professores primários. Nesse contexto, os manuais constroem e fazem circular saberes que produzem e, ao mesmo tempo, são produtos (SILVA, 2005) de uma cultura escolar (JULIA, 2001; FRAGO e ESCOLANO, 1998; ESCOLANO, 2000) então disseminada. Se o projeto de Estado enuncia como deve ser a escola e, no decorrer dos anos, vai constituindo os elementos desse modelo, com as classes graduadas, o método simultâneo, a seriação dos estudos, os sistemas de avaliação e hierarquização dos estudantes, os manuais pedagógicos ensinam os professores a se comportarem corretamente, organizando as classes, 
desenvolvendo os programas escolares, disciplinando os alunos.

Foi justamente para libertar o ensino primário do "descuido, a que tinha estado condenado entre nós" que Antônio Marciano da Silva Pontes dá "pela segunda vez à estampa [seu] pequeno Compêndio de Pedagogia", em 1873. Seu texto "é das primeiras tentativas, que sobre este assunto se tem feito no Brasil, onde à exceção de algumas pequenas traduções de ligeiras obras estrangeiras, nada havia, que pudesse servir de guia ao professor novel em sua difícil e árdua carreira." (Pontes, 1873, p.III). Suas páginas recomendam maneiras de ser professor. Elas estão organizadas em 14 princípios, claramente ordenados. Citemos ao menos alguns:

$1^{\mathrm{o}} \mathrm{Um}$ bom mestre sempre tomar interesse pelo ensino de seus discípulos; e estes devem estar convencidos e que o faz sinceramente.

$2^{\mathrm{o}}$ Preparar bem as lições antes de entrar para a classe, principalmente se versarem sobre matérias, em que alguma dificuldade, imprevista o poderia embaraçar diante de seus discípulos.

$3^{\circ} \mathrm{O}$ professor zeloso e inteligente nunca está contente do que sabe, porque na verdade sempre terá que aprender. Deve pois estudar constantemente, sob diversas faces as mesmas matérias do ensino. (PONTES, 1873, p. 87)

Para fazer funcionar a escola primária, Pontes (1873) enumera outros onze princípios para o professor iniciar o magistério, lidar com seus alunos, estudar e desenvolver a matéria. O compêndio explicita como são os métodos didáticos de acordo com sua organização - individual, simultâneo, mútuo ou misto - e com seu objeto - método de escrita, aritmética, gramática e geometria plana. Traz recomendações para o ensino religioso, de geografia, de desenho linear. Dedica seus dois últimos capítulos à organização da escola, do material e do tempo, bem como à classificação dos alunos e à disciplina. Outros títulos à época são semelhantes.

Em 1887, o padre Camillo Passalacqua publica a Pedagogia e metodologia (teórica e prática) - compreendendo a higiene escolar, 
organização geral e a direção particular das escolas, de acordo com os sistemas modernos de ensino e com os princípios das ciências fisiológicas, psicológicas e morais para uso dos alunos da Escola Normal de S. Paulo. Ele apresenta seu texto como "um livro de ciência", explicando que os "processos científicos e a ordem que demos à marcha educativa [...] não são meras teorias de gabinete; têm elas a consagração de muitos anos da prática", (PASSALACQUA, 1887, p.VII). "Em toda nossa vida de educador, nos esforçamos sempre por acompanhar a marcha natural e progressiva dos nossos educandos: aí estão eles para atestar o que dizemos" (PASSALACQUA, 1887, p.VII). Por isso, o autor afirma: "Consideramos em todo tempo a criança o livro vivo do mestre" (PASSALACQUA, 1887, p.VII) e, ao longo das páginas de seu livro, compila os preceitos a serem seguidos pelos professores nas aulas primárias.

Aproximadamente trinta anos passados das edições dos livros de Pontes (1873) e Passalacqua (1887), Felizberto de Carvalho coordena o Tratado de Metodologia. A terceira edição é de 1909, tendo sido "revista por um professor", tal como se anuncia. O autor apresenta o texto assinalando "a difícil missão de ensinar", resumindo ideias de autores da área e "observações que nos pareceram convenientes, e que decorrem de nossa experiência no exercício de 17 anos de magistério" (CARVALHO, 1909, p.7). É a valorização do saber-ensinar que guia os manuais, preocupados em "concorrer para a precisa elevação do nível da instrução primária entre nós" (CARVALHO, 1909, p.7).

Para Dario Vellozo, autor de mais um Compêndio de pedagogia do período, publicado em Curitiba no ano de 1907: o "bom exemplo" é a norma do professor, "bom exemplo nas palavras, bom exemplo nos atos, bom exemplo nos costumes" (VELLOZO, 1907, p.13). É assim que ele inicia um plano de ação para os normalistas. "O Magistério é apostolado: - Sim! o apostolado da Ciência, pela verdade, para a Suprema Justiça. O Magistério é sacerdócio: - Sim! o sacerdócio da Verdade Una, pela Ciência, para a Paz!" (VELlOZO, 1907, p.13). Aos normalistas prescreve um dos princípios de organização dos conteúdos mais característicos da escola de massas, descritos no trecho: 
O ensino deve ser prático e lógico em seu início e fases sucessivas; passareis do concreto ao abstrato, das lições de coisas aos conhecimentos especulativos - preparando a infância para vencer a luta pela vida, blindando-a contra a miséria por negligência, fazendo-a útil em seu evolver de auroras e vitalidades. (VELLOZO, 1907, p. 16).

Poderíamos dizer que os manuais desse momento em que a Escola Normal e a escola primária começam a se estruturar, se querem como livros práticos e divulgadores de ciência? Em alguns casos sim, como evidenciam as palavras de Pontes (1873), Passalacqua (1887), Vellozo (1907) e Carvalho (1909). Mas as Lições de pedagogia, de Valentim Magalhães (1900), também publicadas à época, trazem um elemento relativamente novo, desenvolvendo uma parte do livro toda dedicada à psicologia. Embora a presença da psicologia desde os primeiros manuais seja invocada e em alguns casos ocupe parte do conteúdo de algumas obras, muitas vezes os procedimentos aconselhados ou descritos parecem sustentados apenas pelo senso comum. E a explicitação da estrutura dedutiva que sustentará a fórmula de ligação entre os preceitos da psicologia sobre a aprendizagem e as escolhas ou consequências para o ensino não aparecerá de maneira afirmada, mesmo nos primeiros manuais que enfatizam a necessidade de conhecer a criança, suas especificidades de comportamento e possibilidades educativas.

Alguns dos livros foram publicados para que os professores seguissem os programas de instrução, cumprissem seus horários, avaliassem seus alunos, lhes atribuíssem notas, mantivessem a sala de aula em ordem. Mas isso não é tudo. Embora destinados a um uso escolar, tais títulos são marcados por diferentes preocupações e modalidades de discurso, não havendo um consenso acerca de suas finalidades. Ora enfatizam as orientações sobre como proceder em sala de aula, como Passalacqua (1887), Pontes (1873) e Vellozo (1907), ora assumem um caráter mais teórico, como no caso de Valentim Magalhães (1900). Cabe perguntar, portanto, sobre os modos como os discursos definem os "saberes" ideais do magistério. Para isso é que se analisam as características dos textos, articulando-as com a história das ciências da educação, a história da 
profissionalização dos professores e da difusão da escola moderna.

Não seria possível compreender os manuais pedagógicos sem considerar suas condições de produção e as opções delineadas na construção dos conhecimentos que veiculam. Para António Nóvoa (1998), essa é uma das tensões que marcam historicamente o campo das ciências da educação, em debates que ocorrem em diversas partes do mundo e em diferentes instâncias de produção e circulação do pensamento educacional. Não se coloca aqui a necessidade de resolver essas tensões, mas antes de entender suas configurações. Houve momentos em que os manuais dos professores quiseram ser divulgadores de ciência (SILVA, 2005). A pedagogia foi considerada a ciência da educação (ARAÚJO, 2017) e outras ciências, notadamente a psicologia, foram chamadas para compor as leituras da Escola Normal. Ao percorrermos os títulos publicados em diferentes tempos e lugares, nós nos damos conta de que nem sempre foi assim, como já se disse.

\section{METÁFORAS E COMPARAÇÕES QUE ENSINAM A ENSINAR, ENTRE A "ARTE PRÁTICA" E A "CIÊNCIA"}

Talvez não seja exagero retomarmos mais uma vez nossa pergunta original. Poderíamos chamar um manual pedagógico de livro, a partir do que sugere Rivière (2004)? Que tipo de leitura esse texto produz entre os professores? De que maneira ele constrói e põe a circular os saberes que fundamentam o magistério? Para responder a pelo menos parte dessa questão, vale a pena uma nova incursão sobre os manuais, observando em suas páginas como definem os saberes da docência. Aqui, a leitura dos cinco títulos evidencia a recorrência das metáforas e comparações. São elas recursos linguísticos largamente utilizados nos manuais e em outras modalidades de textos da ampla e complexa literatura pedagógica. Inspiradas nas contribuições de Charbonnel (1983), Hameline (1986) e Scheffler, nosso desafio é responder essa pergunta, 
mapeando as metáforas e comparações que, como diria Hameline (1986), habitam, animam e consomem esses textos. Os seus usos vão para além de uma retórica designando uma ideia pelo nome de uma imagem com a qual se assemelha. Elas podem indicar como os manuais guiam o magistério e imprimem as finalidades da pedagogia e da metodologia. Tanto Hameline (1986) quanto Charbonnel (1983) assinalam o "jogo metafórico" como uma estratégia discursiva, que permite persuadir melhor o leitor. Identificar metáforas e comparações nos livros dos professores é um exercício profícuo para compreender como se constróem os argumentos e a identidade dos saberes educacionais.

Lembremo-nos das formas pelas quais Israel Scheffler, n'A Linguagem da Educação (1974), diferencia as metáforas dos slogans e das definições que, no seu entender, povoam os discursos da área. Para ele, os recursos metafóricos "indicam aquilo que se pensa serem paralelos significativos, analogias e similaridades existentes no interior do tema do próprio discurso" (SCHEFFLER, 1974, p. 59). Já se disse que as metáforas organizam a reflexão e a explicação em diversos contextos científicos. Numa via dupla de condensação e expansão dos sentidos vemos sua presença nos manuais pedagógicos, em tentativas de estabelecer as especificidades da educação, seu alcance científico, a missão do magistério e os fins do ensino. O professor estaria, no exercício de seu papel, mais próximo do jardineiro, do agricultor ou do escultor? Quer seja uma variação das chamadas "metáforas orgânicas” ou das “metáforas artísticas", de acordo com Scheffler (1974) devemos observar os contextos de sua utilização, os sentidos que elas fazem proliferar e o alcance potencial que adquirem ao serem transplantadas de um a outro domínio.

O diagrama abaixo pode nos ajudar a localizar e compreender metáforas e comparações mobilizadas nos manuais pedagógicos. O referido quadro mostra em suas linhas como esses livros representam a pedagogia e a educação. Também sistematiza como o professor, o aluno e o conhecimento escolar são retratados. Assim é possível destacar a natureza das imagens com as quais esses 
temas, distribuídos em sete colunas do diagrama, são apresentados. Isso articula-se em grupos relacionados à agricultura, ao organismo humano, à religião, à medicina, à tecnologia, à iluminação e à escultura. Tal sistematização permite notar o quanto as imagens são usadas nos manuais (dezoito no total) e identificar a recorrência de alguns tipos. Antes do diagrama, apresentamos uma lista numerada das metáforas e comparações e dos livros onde elas aparecem. Isso permite localizá-las com mais facilidade no diagrama.

\section{METÁFORAS E COMPARAÇÕES QUE ENSINAM A ENSINAR}

1. "o mister da pedagogia há de ser uma agronomia humana". (PASSALACQUA, 1887, p.7-8)

2. "Tem-se comparado não raro a educação à escultura. Não aceitamos porém, a semelhança, porque entendemos que educação é a mútua colaboração do aluno e do mestre. O objeto da educação não é como na escultura uma matéria insensível a cinzelar" (PASSALACQUA, 1887, p.24)

3. "É necessário educar sadiamente o físico, nobremente o intelectual, - para que as faculdades morais possam intensificarse e florescer." (VELLOZO, 1907, p.17)

4. "A educação e os sistemas educativos são como as árvores que obedecem as influências climatológicas. Transplantadas vingam mui raramente" (PASSALACQUA, 1887, p.VIII)

5. “... o desideratum do professor é abrir o coração das crianças à piedade" (PONTES, 1873, p.150)

6. Assim como a medicina outra coisa não é mais do que a aplicação das teorias das ciências médicas, assim a educação antes de ser uma arte fecundada pela iniciativa e devotamento do educador, é 
ela uma ciência deduzida das leis gerais da natureza humana... (PASSALACQUA, 1887, p.19)

7. “o preceptor desenvolve os gérmens do bem” (PONTES, 1873, p.4)

8. "O professor deve velar sobre seus discípulos porque é seu anjo da guarda" (PONTES, 1873, p.26)

9. O exemplo do professor é “contagioso entre os meninos" (PONTES, 1873, p.59)

10. "O grão de desenvolvimento intelectual e assimilativo varia de povo a povo, de núcleo a núcleo, de indivíduo a indivíduo.” (VELLOZO, 1907, p.26)

11. "[Escola normal] deu-vos preciosas noções para educardes a infância, fraternalmente, células do corpo social..." (VELLOZO, 1907, p.15)

12. "educar-lhe o coração e a mentalidade" (VELLOZO, 1907, p.16)

13. “criança é uma argamassa mole, maleável como o cimento, mas que, como ele, endurece e guarda a forma, as depressões, os vincos que se lhe imprimem.” (MAGALHÃES, 1900, p.20-21)

14. Consideramos em todo tempo a criança o livro vivo do mestre (PASSALACQUA, 1887, p.IX)

15. "as crianças são verdadeiras chapas fotográficas sensibilizadas" (MAGALHÃES, 1900, p.21)

16. "seria inútil a mais suculenta lição se não tivesse muita clareza (PONTES, 1873, p.12)

17. "Sabeis como apresentar à criança o doce e delicioso pomo da árvore da ciência” (VELLOZO, 1907, p.16)

18. "Que luzes verdadeiras, que exato conhecimento do homem, que 
virtudes de fino quilate precisa reunir aquele que, sem se iludir acerca de suas forças, se entrega à tão nobre missão" (PONTES, 1873, p.4-5)

Tabela 1: Metáforas e comparações que ensinam a ensinar

\begin{tabular}{|c|c|c|c|c|c|c|c|}
\hline & $\begin{array}{l}\text { AGRICULT } \\
\text { URA }\end{array}$ & $\begin{array}{l}\text { ORGANISM } \\
\text { O HUMANO }\end{array}$ & RELIGIÃo | & $\underset{\text { A }}{\text { MEDICIN }}$ & $\begin{array}{l}\text { TECNOLO } \\
\text { GIA }\end{array}$ & $\begin{array}{c}\text { ILUMINAÇ } \\
\tilde{\text { ÁO }}\end{array}$ & $\begin{array}{c}\text { ESCULTUR } \\
\text { A }\end{array}$ \\
\hline Pedagogia & 1 & & & & & & \\
\hline Educação & $\begin{array}{l}3 \\
4\end{array}$ & & & 6 & & & 2 \\
\hline Professor & 7 & 5 & 8 & 9 & & 18 & \\
\hline $\begin{array}{c}\text { Criança } \\
\text { Aluno }\end{array}$ & 10 & $\begin{array}{l}11 \\
12\end{array}$ & & & $\begin{array}{l}14 \\
15\end{array}$ & & 13 \\
\hline $\begin{array}{c}\text { Conhecim } \\
\text { ento } \\
\text { escolar }\end{array}$ & $\begin{array}{l}16 \\
17\end{array}$ & & & & & & \\
\hline
\end{tabular}

Fonte: elaborado pelas autoras.

Nota-se uma grande variedade de definições apresentadas para a educação e a pedagogia, incluindo-se também a psicologia, no caso específico do manual de Valentim Magalhães (1900). Os autores vão circunscrevendo as diferentes áreas e estabelecendo subdivisões que visam a simplificar o entendimento para seus leitores. Eles extraem daí as consequências para propor os modos de atuação dos professores. Mais do que um fenômeno restrito a esses livros, a proliferação de definições, suas contradições e ambiguidades parece ser uma característica marcante do pensamento educacional do período e, podemos dizer, fenômeno extensivo com configurações múltiplas e transformadas em vários momentos da história da produção educacional brasileira. Podemos nos valer das observações de Nanine Charbonnel (1988) em Pour une critique de la raison éducative, na análise das produções francesas datadas de 1879 a 1911. Ela diz ser possível constatar grandes ambiguidades pela leitura desses textos de diferentes autores que têm na obra de G. Compayré a primeira data e 
abriga em seu conjunto dentre outros, nomes como os de F. Pécaut, H. Marion, F. Buisson e E. Durkheim. A lista é longa: mas é útil transcrevê-la aqui: “ambiguidades na concepção de 'ciência da educação', - ambiguidades na concepção do que é uma ciência, -ambiguidades na concepção da psicologia, ambiguidades na concepção da ética.” (CHARBONNEL, 1988, p. 21).

A autora exemplifica sua ideia tomando nos vários autores a oscilação dos termos e o que chama de "confusão entre todos os saberes". Basta acompanharmos suas observações a propósito da questão quando examina a aula inaugural de $\mathrm{H}$. Marion em 1883 e seu artigo sobre a pedagogia no Dictionnaire de pédagogie de F. Buisson (1887). A aula começa com um jogo de palavras, identificado por Charbonnel. Diz Marion: "Há uma 'ciência da educação', isto não quer dizer 'A educação é uma ciência”. E acrescenta: "‘A educação não é uma ciência (...) ela é uma arte de vez que se propõe essencialmente fins práticos" (MARION, 1883 apud CHARBONNEL, 1988, p.21).

No caso brasileiro, um tal desacordo aparente impregnará as discussões para além do século XIX e irá assumir configurações diversas que questionam até mesmo a necessidade de instituições e cursos específicos para a formação. Charbonnel (1988) nos mostrará a oscilação dos argumentos nos diversos autores. Não cabe aqui reproduzir o extenso quadro das questões ligadas ao estatuto epistemológico da ciência da educação e da pedagogia. Podemos ainda assim, para exemplificar a magnitude do quadro acompanhar como H. Marion (interpretado pela autora citada) acaba por entender o problema. Nas palavras de Charbonnel: " Ciência de fins e ciência de meios, ciência de leis e ciência de regras, ciência da natureza humana e ciência moral, a ciência da educação, tal como a concebe o primeiro detentor da cadeira com esse nome, tem um estatuto suficientemente impreciso para que cem anos mais tarde, o equívoco não tenha sido superado” (1988, p.28). No cuidadoso exame são rastreadas as relações entre os diversos componentes da educação e da pedagogia e suas peculiaridades. 
Se examinarmos o livro do padre Passalacqua, datado de 1887 Pedagogia e Metodologia - encontraremos ali fartas definições que circunscrevem os domínios da educação e da pedagogia. Como obra de um religioso exemplifica o fenômeno da dominância de profissionais advindos dos espaços da Igreja, do Direito e da Medicina no trato de questões educacionais. Como sabemos, algum tempo ainda transcorre para que se constate a presença mais forte dos educadores na produção dos livros destinados à formação docente (SILVA, 2005). Precedido por uma espécie de prefácio na forma de carta escrita por um também padre - J. J. Senna Freitas - neste, começamos a nos deparar com os fins e ações característicos da educação: "o mister da pedagogia há de ser uma agronomia humana” (PASSALACQUA, 1887, p.7-8). As metáforas botânicas depois se multiplicam no interior da obra. Cultivar, fortificar e aproximar da perfeição natural consistem em finalidades a serem perseguidas. Ganham destaque também as imagens da "alma" e do "espírito" frequentemente evocadas.

A pedagogia aparece então comparada à agricultura e à medicina. Para sustentar a necessidade de uma fundamentação científica o autor indaga: "Como cultivar o agricultor um campo se não lhe conhece a natureza produtora do solo? (PASSALACQUA, 1887, p. 5). Dos conhecimentos pedagógicos fazem parte assim a psicologia e a filosofia que fornecem o necessário entendimento sobre o desenvolvimento, as possibilidades, os fins desejáveis e os meios para o alcance da perfeição humana possível. Mais adiante sabemos que a pedagogia, como ciência da educação, admite em si uma parte teórica e uma parte prática. Nas suas palavras:

Assim como a Medicina outra coisa não é mais do que a aplicação das teorias das ciências médicas, assim a educação, antes de ser uma arte fecundada pela iniciativa e devotamento do educador, é ela uma ciência deduzida das leis gerais da natureza humana, leis descobertas pela investigação e pela experiência (PASSALACQUA, 1887, p. 6)

Dedicando a primeira parte das suas Lições de pedagogia à 
psicologia, Valentim Magalhães insere um elemento relativamente novo àquilo que se definia como os saberes pedagógicos e traz, no bojo de suas explicações, metáforas e comparações ainda não encontradas. Passalacqua (1887) e Pontes (1873) assinalam a pedagogia como ciência da educação e mobilizam imagens da agricultura, da religião e da medicina para dimensionar o trabalho docente. Para Pontes (1873), por exemplo, ele é um "anjo da guarda" que desenvolve os "gérmens do bem" e seu exemplo é "contagioso".

Numa outra perspectiva, as lições ditadas por Valentim Magalhães às alunas da Escola Normal no ano de 1899 - e publicadas em 1900, dedicam-se inteiramente à psicologia, sem menção alguma à pedagogia ao longo do texto, embora ela conste do título do manual. Vale notar que as descrições de Magalhães tendem a ser mais objetivas. É assim que explica a psicologia e seus objetos. É assim que parte da noção de alma e espírito, pois a "psicologia [grifos dele] é a ciência que estuda os fatos de espírito, a ciência da alma ou dos fatos anímicos" (MAGALHÃES, 1900, p.7). As lições prosseguem organizadas em capítulos, tratando da "divisão e classificação dos fenômenos psicológicos" (capítulo II); dos "fenômenos da atividade", "instinto e vontade" (capítulo III); da "sensibilidade" (capítulo IV); da "classificação dos sentimentos" (capítulo V); da "inteligência", com a "classificação das faculdades intelectuais" (capítulo VI); das chamadas "faculdades aquisitivas" (capítulo VII); das de "conservação" (capítulo VIII); "de elaboração" (capítulo IX) e, por fim, da "atividade voluntária" (capítulo XX).

\footnotetext{
${ }^{5}$ É comum encontrar a metáfora do "contágio" na literatura educacional. A propósito dela, curiosamente, valeria a pena transcrever aqui um trecho da autobiografia de B. F. Skinner (1904-1990). Falando sobre uma visita que tinha feito à senhora que foi sua professora, no primário, e que tinha tuberculose descreve todas as impressões que teve e reflete: "Às vezes, o ensino é apresentado como uma espécie de contágio. Dizemos que o professor contagia o estudante com o seu interesse pela arte ou o seu amor por Shakespeare. Como professor, com frequência tive que fazer exame para ver se tinha tuberculose e o teste epidérmico sempre dava positivo ainda que os raios $\mathrm{X}$ mostrassem os pulmões íntegros. Contagiou-me realmente a senhorita Graves com algo mais do que o amor à literatura e à arte, com algo mais do que uma ideia da Bíblia como literatura? Em certa medida esperava que fosse assim. Mas onde estaria a análise que pudesse revelar esses outros contágios?” (Skinner, 1980, p.220). Não deixa de ser digno de observação que as dimensões invocadas no caso, para as uteis e férteis influências do ensino, escapem ao previsível se pensarmos que para o autor de Tecnologia do Ensino um bom guia para os professores concretizarem seu trabalho pedagógico seria uma minuciosa descrição de contingências de reforço para instaurar ou extirpar comportamentos.
} 
Os temas dos escritos de Magalhães diferem dos que povoam os manuais de Pontes (1873) e Passalacqua (1881), mais preocupados com questões de ordem moral. Nas Lições de pedagogia (MAGALHÃES, 1900) a ênfase deixa de recair na pedagogia e nas qualidades do professor para assinalar as contribuições da psicologia, na primeira parte de suas lições. Para as alunas da Escola Normal, ele ressalta que a:

Psicologia entrou em fase nova, tendo abandonado os domínios nebulosos do racionalismo indefinido, para tomar por base a observação direta dos fenômenos psicológicos, o conjunto dos fatos anteriores quando procura estabelecer o seu determinismo por meio da experimentação (MAGALHÃES, 1900, p. 11, grifos do autor).

Embora sugerindo um tom mais "científico", Magalhães não deixa de se valer da linguagem metafórica. Para definir o objeto primeiro da psicologia, que é a alma, o autor afirma que ela significa "sopro, alento". Retoma frases corriqueiras para assinalar os sentidos da palavra: "alma da festa"; "alma da casa" ou, num sentido contrário, ao se dizer de uma pessoa que ela "é bonita, mas não tem alma" (MAGALHÃES, 1900, p. 7). Alma também é tomada no manual no sentido de "centro, foco", é a "parte mais fina, mais sutil, mais nobre do homem" (MAGALHÃES, 1900, p. 7). Com essas figuras, o que se quer é marcar a parte intelectual humana, "a que domina a corpórea e a dirige através da vida" (MAGALHÃES, 1900, p. 7). Sem poder definir rigorosamente a "alma”, como o próprio Magalhães (1900) afirma, ela é apresentada como sinônimo de espírito. A sua descrição e importância são marcadas pelas imagens do "sopro", do "alento", de uma "força" que impulsiona os homens. Mais adiante, na página 37 de suas lições, Magalhães (1900) insiste na relevância do que a psicologia estuda. A imagem da "luz" é evocada, assinalando o significado da consciência e suas relações com a alma e o espírito:

Compayré encontra uma comparação feliz para explicar a consciência, dizendo que ela é para o espírito o que a luz é para a chama: quanto 
mais se acelera a combustão tanto mais intensa é a chama, mais brilhante é a luz. Quer dizer isso que à proporção que as faculdades psicológicas se desenvolvem, a consciência se torna mais clara e mais forte (MAGALHÃES, 1900, p. 37).

A vontade, outro objeto da psicologia, coloca-se como ponto fundamental para o professor porque: "Educar a vontade é talvez mais necessário ainda que educar a inteligência, porque esta sem aquela é como uma espada de aço fino na mão de um cadáver, ou um cofre repleto de gemas preciosas... enterrado no solo ou no fundo do mar"6 (MAGALHÃES, 1900, p.51).

Ao marcar as especificidades e importância da psicologia para o professor, Magalhães aproxima-a da filosofia e da fisiologia, mobilizadas inúmeras vezes no manual. Os diálogos entre essas áreas são explicitados em vários momentos, especialmente quando Magalhães explica que: "Os fenômenos relativos àquele (corpo) constituem o domínio da Fisiologia, e os referentes a esta (alma) os da Psicologia. As relações entre uns e outros são íntimas e constantes, e é devido à estreiteza dessas relações que a alma e o corpo exercem influência recíproca” (MAGALHÃES, 1900, p.10, grifos do autor). O livro abriga imagens que, de modo significativo, repetem outras usadas anteriormente. Orientando suas alunas, futuras professoras, Magalhães recomenda "o maior escrúpulo da parte do educador em arraigar os hábitos bons e evitar os maus, porque deles depende a direção e o aproveitamento da vontade" (MAGALHÃES, 1900, p.20). Daí a necessidade de o professor ensinar através dos seus "hábitos", que assumem assim

importância capital na educação, por ser a habitualidade uma força que, como todas as outras da natureza física, - a água, o fogo, o vento aproveitada para o bem produz verdadeiros prodígios, mas desviada para o mal pode ser causa de irreparáveis calamidades (MAGALHÃES,

\footnotetext{
${ }^{6}$ As metáforas expressas nessa afirmação possuem uma força intensa. Porém, não as incluímos no diagrama apresentado no presente artigo e intitulado Metáforas e comparações que ensinam a ensinar, porque essas imagens fazem referência à educação moral. Em nosso esquema, consideramos as imagens referentes à pedagogia, educação, professor, aluno e conhecimento escolar.
} 
1900, p. 20).

Isso porque a "criança é uma argamassa mole, maleável como o cimento, mas que, como ele, endurece e guarda a forma, as depressões, os vincos que se lhe imprimem.” (MAGALHÃES, 1900, p.21). A argamassa mole e o cimento são usados aqui em sentido parecido com o da famosa metáfora da cera e da modelagem. E a eles acrescenta-se outra imagem, a das chapas fotográficas, elemento relativamente novo, mais ligado a uma tecnologia. Para se ter uma noção de como Magalhães mobiliza essa imagem, convém transcrever:

Todos os psicologistas afirmam que as primeiras impressões são as que perduram, que é na infância que o ensino mais aproveita, que as crianças são verdadeiras chapas fotográficas sensibilizadas que recebem, que guardam indelevelmente as imagens que nelas se refletem. De tudo isso se conclui que o hábito é um grande elemento de educação, merecedor da máxima atenção e do mais esmerado cultivo (MAGALHÃES, 1900, p.21, grifos nossos).

Neste trecho de Magalhães (1900) e em várias outras passagens extraídas de manuais pedagógicos do período estão colocadas representações acerca dos alunos, dos saberes a serem ensinados, do magistério. Aqui, foi possível analisar as metáforas e comparações a partir das quais esses títulos definem a razão e a identidade do trabalho docente e da pedagogia.

Para finalizarmos nossas reflexões, vale sublinhar mais uma vez a pergunta de Rivière (2004) a propósito dos livros que ensinam a cozinhar, aproximando-os dos textos que ensinam a ensinar. Os manuais pedagógicos poderiam ser chamados de livros? Um livro prático, talvez. Retomando estudos já realizados (SILVA, 2019, 2018, 2017) e propondo novas incursões, o presente artigo traz elementos para as discussões sobre a "utilidade" da pedagogia, muitas vezes acusada de ser pura "verbiagem" ou mero receituário. Os manuais aqui examinados circunscrevem as tentativas de definir a pedagogia como disciplina (CHERVEL, 1990) caracterizada ora como "arte prática", ora como 
um saber científico e, portanto, mais legítimo.

Mapeamos metáforas e comparações usadas nas páginas dos manuais e, com isso, foi possível identificar as similaridades postas entre a pedagogia e a agronomia ou a medicina. Ali são notáveis os paralelos entre o professor e um missionário ou um agricultor. São abundantes as analogias entre a criança/aluno e a argila, a argamassa mole ou a chapa fotográfica, nas quais é possível imprimir marcas. Também são marcantes as proximidades postas entre o que se ensina com imagens orgânicas, como as da "suculenta lição" ou as do "doce e delicioso pomo da árvore da ciência". Poderíamos pensar que a profusão de metáforas e comparações deve-se a uma certo estilo próprio do tempo e presente em vários textos das ciências humanas, ou ao intuito de conclamar os leitores a uma ação dirigida para o êxito ou ainda à tentativa de envolver os professores (e futuros professores) numa linguagem quase poética em que se multiplicam alusões, aproximações e sugestões. Poderíamos dizer que a linguagem dos manuais é vaga e imprecisa ao falar de ciência e arte da educação? Mas a linguagem utilizada por eles visa exatamente facilitar a compreensão. Que se diga, no entanto, que não é pela objetividade das definições que tal ocorre. Ainda seria preciso deter-se mais em identificar, à moda de Certeau (1998), talvez, a diversidade da "língua da educação", tal como mostrado em A invenção do cotidiano (CERTEAU, 1998), quando o autor fala das regras da arte e da culinária. Mas, a educação seria sempre um caso em que é preciso falar de uma coisa remetendo a outra? A razão pedagógica, de fato, pode não ser a razão das ciências em que se tem buscado sustentação. As razões didáticas também não se querem como dedução. É preciso então comparar, aludir e tentar aproximações? Nos manuais foi assim, como foi possível mostrar no breve período aqui examinado.

\section{FONTES}

CARVALHO, Felizberto. Tratado de metodologia. RJ: Livraria Francisco 
Alves, 1909.

MAGALHÃES, Valentim. Lições de pedagogia. Primeira parte - psicologia.

RJ: Laemmert \& C. Editores, 1900.

PASSALACQUA, Camillo. Pedagogia e metodologia. SP: Tipografia a vapor de Jorge Seckler \& Comp. 1887.

PONTES, Antonio. Compêndio de pedagogia. $3^{\mathrm{a}}$ ed. RJ: Tipografia da reforma, 1873 .

VELLOZO, Dario. Compêndio de pedagogia. Curitiba: Governo do Estado do Paraná/Congregação da Escola Normal, 1907.

\section{LIVROS DE CULINÁRIA}

BENTA, Dona. Dona Benta - comer bem. $77^{\mathrm{a}}$ ed. SP: Companhia Editora Nacional, 2013.

CAROSELLA, Paola. Todas as sextas. SP: Ed. Melhoramentos, 2016.

HORTA, Nina. Não é sopa - Crônicas e receitas de comida. SP: Companhia das Letras, 1995 .

HORTA, Nina. O frango ensopado da minha mãe, SP: Companhia das Letras, 2015).

\section{REFERÊNCIAS}

ARAÚJO, José Carlos. A pedagogia: ciência da educação, sua genealogia entre os séculos XVII e XX. In: SIQUELLI, S. e outros (org.) Fundamentos da educação. Uberlândia: Navegando Publicações, 2017, p. 49-84.

BASTOS, Maria Helena Camara. Manual para os Jardins de Infância: Ligeira Compilação pelo Dr. Menezes Vieira -1882. PA: Redes Editora, 2011.

BASTOS, Maria Helena Camara. A formação de professores para o ensino mútuo no Brasil: o "Curso normal para professores de primeiras letras do Barão de Gérando (1839). Revista História da Educação. v.2, n.3, jan-jun/1998. p.95-119. 
CERTEAU, Michel de. A invenção do cotidiano. Tomo II. Morar, cozinhar. SP: Vozes, 1998

CHARBONNEL, Nanine. Les aventures de la métaphore. In: La Tâche aveugle. T1, Strasbourg: PUS, 1991.

CHERVEL, André. História das disciplinas escolares. Teoria \& Educação, 2, 1990, p.177-229.

DUSSEL, Inês; CARUSO, Marcelo. A invenção da sala de aula. SP: Moderna, 2003.

ESCOLANO, Agustin. Las culturas escolares del siglo XX. Encuentros y desencuentros. Revista de Educación, $\mathrm{n}^{0}$ extraordinario, 2000, p.201-218.

FRAGO, Antonio Vinao.; ESCOLANO, Agustin. Currículo, espaço e subjetividade. RJ: DP\&A, 1998.

FRANÇA, Franciele. Um inventário de saberes, um repertório de fazeres: Modos e práticas do ofício de ensinar na escola primária durante a segunda metade do século XIX (1856-1892). Curitiba: UFPR, 2019, tese de doutorado.

GARCIA, Tânia. Criteria used by teachers in Brazilian elementary schools in the process of textbook selection. Orbis Scholae (Online), v. 8(2), p. 9-2, 2014.

GATTI JR., Décio. O Ensino de História da Educação no Brasil: fontes e métodos de pesquisa. Cadernos de história da educação (online), v. 16, p. 064-088, 2017.

GATTI JR., Décio. Investigar o Ensino de História da Educação no Brasil: categorias de análise, bibliografia, manuais didáticos e programas de ensino (Séculos XIX e XX). In: GATTI JR., D.; MONARCHA, C.; BASTOS, M. H. (Org.) $O$ ensino de história da educação em perspectiva internacional. Uberlândia: Edufu, 2009, p. 95-130.

GATTI JR., Décio. Percurso histórico e desafios da disciplina história da educação no Brasil. In: GATTI JR., D.; PINTASSILGO, J. (Org.). Percursos e desafios da pesquisa e do ensino de história da educação. Uberlândia/MG: EDUFU, 2007, p. 99-139.

DUARTE, Bruna. e GATTI JR, Décio. Manuais escolares, formação de professores e concepção clássica de modernidade: as Noções de História da Educação de Afrânio Peixoto no Brasil na década de 1930. Revista Educação e Fronteiras on-line, v. 7, p. 145-166, 2017. 
HAMELINE, Daniel. L'Education, ses images et son propos. Paris: Éditions ESF, 1986.

HEGETO, Léia. A Didática como disciplina escolar: estudo a partir dos manuais de Didática Geral. Curitiba: UFPR, 2014. tese de doutorado.

JULIA, Dominique. A cultura escolar como objeto histórico. Revista Brasileira de História da Educação, $n^{\circ}$ 1, jan. /jun., 2001, p. 9-43.

NÓVOA, Antonio. Professionalisation des enseignants et sciences de l'éducation. In: Histoire \& comparaison (essais sur l'éducation). Lisboa: Educa, 1998, p.121-146.

NÓVOA, Antonio. Le temps des professeurs. Lisboa: INIC, 1987.

NÓVOA, Antonio; SCHRIEWER, Jürgen. (eds) A difusão mundial da escola. Lisboa: Educa, 2000.

REBOUL, Olivier. Qu'est-ce qu'apprendre? Paris: PUF, 2001.

RIVIÈRE, Jean Loup. Le gôut et l'idée.In: La gastronomie, critique, juinjuillet, 2004 .

SCHEFFLER, Israel. A linguagem da educação. São Paulo: EDUSP, 1974.

SKINNER, Buurhus Frederic. Autobiografia, Vol.1. Barcelona: Editorial Fontanella, 1980.

SILVA, Vivian. História de leituras para professores: um estudo da produção e circulação de saberes especializados nos "manuais pedagógicos" brasileiros (1930-1971). SP: FEUSP, 2001, dissertação de mestrado.

SILVA, Vivian.. Livros que ensinam a ensinar: um estudo sobre os manuais pedagógicos brasileiros (1930-1970). SP: Appris, 2019.

SILVA, Vivian.. Saberes em viagem nos manuais pedagógicos: construções da escola em Portugal e no Brasil (1870-1970). SP: FEUSP, 2005, tese de doutorado.

SILVA, Vivian. Saberes em viagem nos manuais pedagógicos: construções da escola em Portugal e no Brasil (1870-1970). SP: Editora UNESP, 2018.

SILVA, Vivian.. A Didática e os textos para formar professores. SP: FEUSP, 2017. tese de livre-docência.

SILVA, Vivian; PEREZ, Tatiane. Apropriações dos saberes pedagógicos no início 
da formação: manuais e provas da Escola Normal de São Paulo (década de 1870). História da Educação. vol. 18, n.42. jan-abr/2014. p.93-113.

TARDIF, Maurice. Saberes profissionais dos professores e conhecimentos universitários: elementos para uma epistemologia da prática profissional dos professores e suas conseqüências com relação à formação do magistério.

Revista Brasileira de Educação, jan-mar/2000, nº 13, p. 5-24.

TEIVE, Gládys.; OSSENBACH-SAUTER, Gabriela. Contextos de recepção e interpretação dos manuais escolares: caminhos teórico-metodológicos para a investigação sobre os manuais escolares na perspectiva da cultura escolar.

Revista História da Educação (on-line), 2016, 20(50).

TREVISAN, Tábatha. A pedagogia por meio da Pedagogia: teoria e prática (1954) de Antônio D `Ávila. SP: Faculdade de Filosofia e Ciências/UNESP, Marília, 2007. dissertação de mestrado.

VALDEMARIM, Vera. O manual didático Práticas Escolares: um estudo sobre mudanças e permanências nas prescrições para a prática pedagógica. Revista Brasileira de História da Educação, v. 17, p. 13-39, 2008.

VIVIAN BATISTA DA SILVA é professora da Faculdade de Educação da Universidade de São Paulo. Doutora em Educação pela Universidade de São Paulo, com período de sanduíche realizado na Universidade de Lisboa. Estágio de pós-doutorado sênior realizado na Universidade Federal do Paraná.

E-mail: vivianbs@yahoo.com

(D) http://orcid.org/0000-0002-5509-2008

DENICE BARBARA CATANI é professora Titular aposentada da Faculdade de Educação da Universidade de São Paulo. Doutora em Educação pela Faculdade de Educação da Universidade de São Paulo

E-mail: dbcat@usp.br

(b) http://orcid.org/0000-0001-6019-8969 
Revista História da Educação (Online), 2019, v. 23: e93223

DOI: http://dx.doi.org/10.1590/2236-3459/93223
e-ISSN: $2236-3459$ http://seer.ufrgs.br/asphe

\footnotetext{
(C) (1)

Revista História da Educação - RHE

Associação Sul-Rio-Grandense de Pesquisadores em História da Educação - Asphe

Artigo de acesso aberto distribuído nos termos de licença Creative Commons.
} 